\title{
The Application of Mnemonic to Improve the Middle School Student's English Achievement
}

\author{
Youzhi $\mathrm{Du}^{1}$ \\ ${ }^{1}$ Changsha Youzhi memory school, Changsha, China \\ Correspondence: Youzhi Du, Changsha Youzhi memory school, Changsha, 2111 Weiyi Star International, \\ Shaoshan North Road, Changsha, 410011,China. Tel: 86-0731-8413-9668. E-mail: cjjyfa@126.com
}

Received: June 21, 2012

Accepted: August 30, $2012 \quad$ Online Published: October 15, 2012

doi:10.5539/jel.v1n2p233

URL: http://dx.doi.org/10.5539/jel.v1n2p233

This material is based upon work supported by the "Tenth Five-Year Plan"of National Education Science, Ministry of Education under Grant No. FHB050742 (Self-education and independent development of academic performance of students).

\begin{abstract}
In order to know the memorizing affection of the mnemonic enhancing the junior and senior students' English learning, select the various methods, and check the effect and the practical use of the means of memory. The present author designed an experiment to attempt to check the extent of how much the student grasp the number of vocabularies how much the students enhance the examination score, and how much the students learn English spontaneously after they applied the application of "ZYD" in English learning.
\end{abstract}

Keywords: ZYD mnemonic, middle school students, improvement achievement of English learning

\section{The Research Envisage}

\subsection{How to Make Use of the "ZYD" Mnemonic to Strengthen the Memory?}

"ZYD" is the acronym of making up the from the first letters of three words "zipper" "yield" and "deftness" with the meaning of "the zipper produces the deftness", which shows the super imagination is the most important way to grasp the high efficiency means of memory.

\subsubsection{The Key of Memory-search}

Search is aimed to look up and extract the content of what people have remembered. The key of memorizing is search and the key of search is organizing information. That is, information is stored regularly and sequentially. As only to store the information according to best way for searching, people can efficiently enhance the memory effect. From the prospect of information processing, the process includes three steps. When sensor is stimulated by the external stimulation, it induce sensation whose trace conserved is working memory. The information stored as the working memory once is focused on, it will transform the short-term memory, and the when information of the short-term memory is retold and coded, it will store as the long-term memory. The information stored as the long-term memory, only to extract the short term memory, it can work. Only to solve the problem of regular and sequential, students should increase the efficiency of searching according to the most efficiency way to store the information. That is the problem that "ZYD" mnemonic chiefly to solve. "Fantastic mental imagery" and "imagination" the two kinds of the ability training aim to establish cards. A serious of particular methods offer imaginary system and coding program to code and arrange the information, so as to achieve the accuracy and celerity.

\subsubsection{The Information Form Which is Easy to Stored-fantastic Mental Imagery}

If people want to really understand and grasp the "ZYD" mnemonic, people should understand the basic principles and be able to apply it proficiently through the basic training. Fantastic mental imagery is one of the most basic and important part of the "ZYD" mnemonic. If a person isn't able to create reappear fantastic metal imagery, the followed particular methods will not be carried out. On the contrary, people with this ability not only grasp the following methods but also create and develop the new methods. Fantastic mental imagery is a kind of vivid, impressive, easy to remembered imagination which the brain process, exaggerate, reduce and 
distort the objects that people have sensed. It is conscious representation and recreation of the objects. The "representation and recreation" includes two implications. One is that the fantastic mental imagination is subjectively controlled by people, and people control when and how it appears. The other implication of fantastic mental imagination is artifactitious factious imaginary which is different from the originate objects. And it is the vivid, strong, bizarre, illogically, particular imagination of controlled by the consciousness through processing which is controlled by person's subjective will.

Fantastic mental imagination is not the presentation of the psychology. People can not understand it idealistic. It is based on the objective reality though it controlled by the consciousness and processed by subjective will. There are no objective things; there is no fantastic mental imagination. The consciousness is the production of the objective things. The understanding of the fantastic mental imagination should not be too narrow. The fantastic mental imagination not only refers to the visual one, but also includes multiaspect property that the sensors sense the objectives. Thus it can be seen, the fantastic mental imagination based on the sense includes the visual one, auditory one, gustatory one, tactile one, inner sense one and comprehensive one, ect. Appearing the fantastic metal imagination isn't a easy task especially for the beginners who can not achieve the effect of the appearing. So, the beginners should have the train about the appearing. Once reaching the standard of appearing easily, people take the vital steps to grasp the "ZYD"mnemonic.

\subsubsection{The Store Way Which is Easy to Extract-imagination}

The main point of memory is imagination. That is, when people see one thing, they can associate with the other thing relating to it. Imagination like hook, it can hook exactly the information people have remembered in their mind. When one thing, once have the particular relation to the other things, it can easily remembered. And other things associated can hook out the information stored in the memory. When the remembered things sink in the sea of the mind, the hook can hook it. The ability of people's memory originates the imagination. The person with the powerful imagination, they have the have the strong imagination. The association is more abundant, the art of memorizing is more excellent. There is researches have showed that imagination has the many common features on the real experience including the retails, emotion awaking with the accompaniment and similar neural characteristics. It has the strong affection on the learning, decision-making and behavior.

The basic method: Making a visible and familiar thing associate with the invisible things. For example: one friend borrower your book and you always forget to mention him to return the book. In order to let you mention him to return the book to you, when you meet him next time, you will image the picture that he stand there with a book on the top of his head. Once you meet him again, you will remember it.

In order to accomplish it we can make use of displacement, contrast, intermediary, visualization, exaggeration, movement, homophone, standard, and analogy.

\subsubsection{The Preparation of Super Memory-relaxion}

Super association method is a kind of high efficiency mnemonic. People remember the things and grasp it mainly depending on thought and imagination. The basic idea of it is that making people to apply the imagination principles and memorial skills to explore human resources through relaxing and adjusting body rhythm, then bringing the function of brain and body into play to make the people to act as a whole part. Super association method has the basic ways which body and brain keep relaxing in state and the same rhythm. When people sit down and began to "absorb" information, the body is in the harmony, rhythmic state to get ready to began the efficiency memory which is applied it to enter the high efficiency preparing state. At the same time, Super association method combines the new item and each element of idiom according to the particular principles, fixed sequence to produce the abundant imagination and vivid association. Thus, the newly remembered will not be effected by the proactive inhibition and the retroactive inhibition. The imagination is more specific and vivid, there is better for organizing, processing, coding and storing to make the short-term memory into the long-term memory stage. It not only increases the amount of memory, but also strengthens the succession of memory, thus it increases rate of the memory.

The knack of "ZYD" mnemonic is changing the way of usually storage and search fundamentally. So its superiority firstly is embodied in building a serious of scientific search system according to artificial way, which make the memory stored as the best convenience way to store, and enhance the rate of the memorial storage. Secondly, the rote memory that people usually remember the things is diminishing movement. Once the memory becoming curb, it will cost more time to remember the thing whose level of difficulty is the same as the one before. If there are ten contents at the same level of difficulty, the tenth content will cost much more time than the first one in remembering. However, using the "ZYD" mnemonic to remember it, the two content will cost the same time, thus it greatly reduce the memory loss. Besides, the content of rote memory should not be too much, 
generally under the limitation of seven, while the amount of the content will not be limited by the "ZYD" which use the idiom to remember. The content is more, the more superiority it shows.

\subsection{Hypothesis Testing}

There are two steps for hypothesis testing.

The first is preliminary test. In order to modify and select the various kind of method and improve the assumption, the "ZYD" mnemonics method which aims to improve the memory effect of the scores of junior and senior students.

The second is experiment. The present author designs an experiment for testing the effectiveness and practicability of "ZYD" mnemonics.

This experiment attempts to discuss (1) the extend of how much the students enhance the English vocabulary scores.(2) the extent of how much the student enhance the English score (3) the extent of how much the student enhance the self-learning study, after the students accept the vocabulary training.

\section{The Experimental Methods}

\subsection{Subjects}

To select randomly 62 junior school students, 64 high school students from the nationwide "ZYD" mnemonics training, according to the English scores before the training, to establish an experimental class and a control class.

\subsection{The Experimental Procedure}

First, randomly select 40 vocabulary the students learned in the half of last term, to test the students' English vocabulary, write down the vocabulary test scores for each class of students (each record 2.5 points), and its English mid-term exam (before the training) scores.

And then training the students, and the training specific process is consistent with the first experiment, the experiments were performed for eight months (from January to the end of August, 2006).

Third, after the completion of training, randomly select 40 vocabulary learned in the second half term, and then to test each class' English vocabulary, and write down the vocabulary scores of all students (remember one of them each record 2.5 points), and write down their final English exam scores. Each of the two vocabulary tests is limited to 12 minutes.

\subsection{Experimental Results}

2.3.1 Before and After Training the Experimental Class in the Control Class Vocabulary Test Scores

Table 1. Each class students' vocabulary test scores in the table before a training

\begin{tabular}{lcccc}
\hline & & Number & $\mathrm{X} \pm \mathrm{S}$ & Difference test(t) \\
\hline \multirow{2}{*}{ Junior Group } & The experimental class & 31 & $71.06 \pm 4.92$ & \multirow{2}{*}{0.89} \\
& Control class & 31 & $72.01 \pm 5.72$ & \\
\multirow{2}{*}{ Senior Group } & The experimental class & 32 & $69.02 \pm 6.25$ & \multirow{2}{*}{1.01} \\
& Control class & 32 & $67.65 \pm 4.85$ & \\
\hline
\end{tabular}

Table 2. Each class students' vocabulary test scores in the table after a training

\begin{tabular}{lccc}
\hline & & $\mathrm{X} \pm \mathrm{S}$ & Difference test $(\mathrm{t})$ \\
\hline \multirow{2}{*}{ Junior Group } & The experimental class & $77.42 \pm 8.21$ & $2.95^{* *}$ \\
& Control class & $69.45 \pm 6.39$ & \\
Senior Group & The experimental class & $87.02 \pm 10.66$ & $7.92^{* *}$ \\
& Control class & $66.95 \pm 9.56$ & \\
\hline
\end{tabular}

Table 1 shows that the English vocabulary scores of the experimental classes and the control classes students in two grades is slightly different, but the difference was not significant, this shows basically the same original 
vocabulary levels of students.

Table II shows, combining English teaching with "ZYD" mnemonics training to students, the secondary students and high school students' English vocabulary scores compared to the respective control class, have a significant increase, and the differences were very significant.

2.3.2 Before and After Training the Experimental Class, Control Class English Test Scores

Table 3. Each class students' English test scores in the table before a training

\begin{tabular}{cccc}
\hline & & $\mathrm{X} \pm \mathrm{S}$ & Difference test $(\mathrm{t})$ \\
\hline \multirow{2}{*}{ Junior Group } & The experimental class & $76.26 \pm 6.37$ & 0.87 \\
& Control class & $77.01 \pm 5.75$ & \\
\multirow{2}{*}{ Senior Group } & The experimental class & $72.25 \pm 3.61$ & 0.86 \\
& Control class & $73.15 \pm 2.42$ & \\
\hline
\end{tabular}

Table 4. Each class students' English test scores in the table after a training

\begin{tabular}{cccc}
\hline & & $\mathrm{X} \pm \mathrm{S}$ & Difference test $(\mathrm{t})$ \\
\hline \multirow{2}{*}{ Junior Group } & The experimental class & $83.89 \pm 7.56$ & $2.82^{*}$ \\
& Control class & $77.32 \pm 8.01$ & \\
Senior Group & The experimental class & $84.08 \pm 11.62$ & $4.36^{*}$ \\
& Control class & $74.12 \pm 10.01$ & \\
\hline
\end{tabular}

Table 3 shows that, before the experiment, the English scores of the secondary and senior experimental classes and control classes are much the same, comparing the two, no significant differences, broadly consistent with the student's original foundation in English.

Table 4 shows that to carry out "ZYD" mnemonics training of English course to the students, the experimental class students' English scores improved significantly. And compared to the respective control class, junior group students have significant difference, and high school group are very significant.

\subsubsection{The Analysis and Discussion}

2.3.3.1 On the Feasibility and Effectiveness to Improve Students' Memory Efficiency and the Culture of Memory Ability

The success of control motivation, learning strategies, time management, physical environment, social environment and learning outcomes of these six aspects determine your learning. Therefore, the "ZYD" mnemonics learners may choose from these six areas for self-cultivation. The "ZYD" memory method is a fast, efficient memory method, this idea, which has been confirmed by this study. This time, during the experiment, we found it a mount of complexity and difficulty to code and extract the English word memory codes, process the information when we use the "ZYD"mnemonics training. Since this approach is often required to produce a rich imagination and a vivid association, which based on a certain amount of vocabulary, therefore, it is more difficult for the junior students to use and master compared to the senior high students. Because they just entered secondary school, the limited vocabulary, coupled with the overall knowledge base is worse than high school students, poor imagination, relatively slow information processing, which can not transformed into a lively and strong associations. However, through systematic training, the junior students can grasp and use them consciously. Precisely because of this, after carrying out "ZYD" mnemonics training to English vocabulary, the secondary experimental class students reached a significant level compared with the control classes, but their English achievement is not as significant as high school experimental classes and control classes. Studies have shown that the ability to remember previous years of experience is influenced by many factors, such as: the type of machining operation in coding, the interaction between encoding and retrieval operations.

\subsubsection{The Impact on Memory Training on the Student's Personality}

In the process of the experiment, we found that "ZYD" mnemonics training can not only help students improve academic performance, but also has a positive effect on the students' character development. The most obvious is 
that it inspires the students' interest and curiosity; Such as English words, which distressed the students, they reflect it is difficult to remember them. The survey that conducted on the experimental class students before the English memory training of the students has a strong demand on it. Precisely because there is such a strong motivation, class students are able to have a good cooperation with the speaker, as requested by the speaker to conduct training. From the method itself, ZYD memory is as far as possible for the Chinese people's habits and linguistic characteristics, using the principles of encoding and conversion, contrasting, standard methods combined with the relaxation exercises, the training of the image; allow it to abstract material, in a pleasant memory in a specific scenario. For this reason, it's easy for the students to firmly remember the history, politics and general knowledge question and lots of vocabulary after training. After testing the memory in the learning, the students will put greater enthusiasm in the course of learning, thus contributing to the overall improvement in academic achievement, thereby improving the English self-learning ability. As an ability, independent study can not only benefit the students from school education, but lay the necessary psychological foundation to its lifelong learning. According to post-training survey $95.2 \%$ of the students said that they have strong learning requirements for this training while originally they were not interested in the courses. And they have greatly improved in English self-learning ability.

\section{References}

Kosslyn, S. M. (1994). Image and Brain: The Resolution of the Imagery Debate. Cambridge, MA: MIT Press.

Duyouzhi. (2006). ZYD Memory Method. Hunan People's Publishing House.

Myron, H. etc. (2000). Self-regulation of Academic Learning in Middle-level Schools. The Elementary School Journal, 100(5), 473-490. http://dx.doi.org/10.1086/499651

Sanquist T., Rohrbaugh J. W., Syndulko K., \& Lindsley D. B. (1980). Electnrucortical signs of levels of processing: perceptual analysis and recog-nition memory. Psychophysiology, 17(6), 68-577. http://dx.doi.org/10.1111/j.1469-8986.1980.tb02299.x

Areglado, J. et al. (1996). Learning for Life: Creating Classrooms for Self-directed Learning (pp. 5-10). Corwin Press Inc. 